\title{
Influence of cell-shape on the cake resistance in dead-end and cross-flow filtrations
}

\author{
Manuel Mota*, José A. Teixeira, Alexander Yelshin \\ Centro de Engenharia Biológica-IBQF, Universidade do Minho, 4709 Braga, Portugal
}

Received 20 June 2001; received in revised form 28 October 2001; accepted 14 November 2001

\begin{abstract}
The problems related to tortuosity variation whenever filter cakes are composed of cells with different shapes and compressible biosuspensions are discussed. Presented examples show that neglecting the tortuosity variation may lead to significant miscalculations of cake porosity or of specific cake resistance. Specific cake resistance of rod-like particles in cross-flow filtration depends on the higher tortuosity obtained by the shear-induced ordered arrangement. In turn, spheroid cells such as baker's yeast cells do not affect tortuosity as much as the rod-shaped cells. By including tortuosity as a parameter of compressible cakes, a more precise representation of cakes' behaviour may be obtained. The tortuosity becomes a highly significant parameter with the increase in filtration pressure. (C) 2002 Elsevier Science B.V. All rights reserved.
\end{abstract}

Keywords: Cells; Membrane filtration; Specific cake resistance; Tortuosity; Porosity

\section{Nomenclature}

$d_{\mathrm{p}} \quad$ particle diameter $(\mathrm{m})$

$J \quad$ filtration flux $(\mathrm{m} / \mathrm{s})$

$K \quad$ Kozeny's coefficient

$n \quad$ compressibility index

$\Delta p \quad$ filtration pressure $(\mathrm{Pa})$

$R_{\mathrm{m}} \quad$ filter medium resistance $(1 / \mathrm{m})$

$T$ tortuosity

$w \quad$ weight of cake per unit filtration area $\left(\mathrm{kg} / \mathrm{m}^{2}\right)$

$\alpha \quad$ average specific cake mass resistance $(\mathrm{m} / \mathrm{kg})$

$\delta \quad$ ratio length/diameter of the particles

$\varepsilon \quad$ porosity

* Corresponding author. Tel.: + 351-253-604405; fax: + 351-253-678986.

E-mail address: mmota@deb.uminho.pt (M. Mota). 
$\mu \quad$ viscosity (Pa s)

$\rho_{\mathrm{s}} \quad$ solid particle density $\left(\mathrm{kg} / \mathrm{m}^{3}\right)(\mathrm{g} / \mathrm{l})$

Indexes

c-f cross-flow filtration

d-e dead-end filtration

\section{Introduction}

Cell filtration from liquid phase is a wide spread operation in biotechnology, food and beverage industry or wastewater treatment. Due to the increasing economic importance of those industries, it is important to provide a correct interpretation of filtration data, mainly, because, it may influence the choice of the filtration method.

Conventionally, separation has to be a multistage process due to the wide ranges of particle size and their concentration. Suspended particles may be divided in three groups $[1,2]$ - (1) particles of a size above $10 \mu \mathrm{m}$; (2) suspended microorganisms such as bacteria and yeast ranging from 0.5 to $8 \mu \mathrm{m}$; (3) colloidal particles of less than $0.5 \mu \mathrm{m}$. Facing increasing environmental problems, as well as higher costs of water and energy, producers are looking for new filtration technologies. This is the case, for example, in brewing industry, where cross-flow membranes are widely used to clarify and stabilise beer $[3,4]$.

Among several filtration methods, dead-end and cross-flow filtrations are the most frequently used in industry (see Fig. 1). The dead-end filtration consists in gradually increasing the cake thickness up to a level determined by pressure drop or flow velocity. In the end, we have a cake and a clarified filtrate. Dead-end filtration is often used as a method to estimate the specific cake resistance for cross-flow filtration and usually gives reasonable data for spherical and ellipsoidal-shaped cells [5].

In cross-flow filtration, the main stream of the suspension is along a direction parallel to the filter medium. The filtrate flow is perpendicular to the main stream and the cake formed is of a limited thickness. In the end, we have a filtrate and concentrated slurry, which needs further dewatering.

Experts mention the cake compressibility as a matter of concern in different areas of industrial application, such as the micro-filtration with cake build-up or the cross-flow filtration with the build-up of a layer on the filtering surface $[6,7]$.

Under the action of pressure drop and frictional drag on the cake particles, the compressible cake phenomena can be enumerated as follows [8,9]: (1) successive particles rearrangement inside the cake under stress; (2) matrix compression in gel-like cakes; (3) complex cases where both the aforementioned phenomena interplay, such as in the case of a biofilm. In every case, the cake structure will be affected by such diverse phenomena as the collapse of the pore structure, pore compression and pore distortion. This set of phenomena will affect in different extent the porosity, the pore size and the pore tortuosity of the filtration cake.

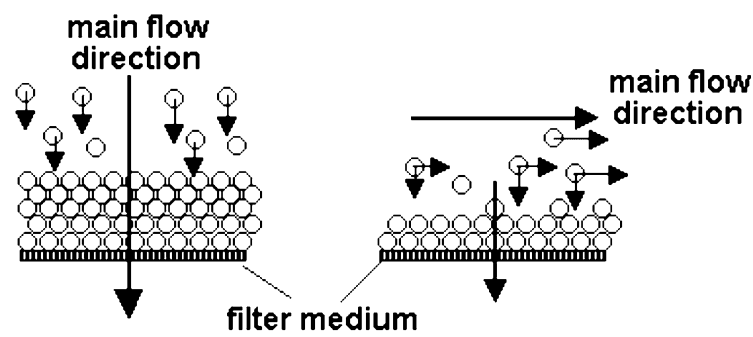

Dead-end filtration

Cross-flow filtration

Fig. 1. Sketch of dead-end and cross-flow filtration. 
So far, the works devoted to the study of cake compressibility did not pay attention to the effect the kind of filtration, on the one hand, and the shape of the particles, on the other, might have on the cake compressibility and on the cake resistance.

In this work, we would like to show some features of filtration of differently shaped and compressible cells in dead-end and cross-flow filtration processes. For the analysis, we have used data published by several authors as well as our own data gathered from filtration experiments with baker's yeast suspensions.

We used in our research commercially available Saccharomyces cerevisiae (baker's yeast) resuspended in an isotonic solution of $\mathrm{NaCl}$. The used yeast cells displayed a narrow size distribution, with a measured average cell size of $5.8 \mu \mathrm{m}$ and a spheroid shape. The determined cell size was close to the size measured by Schluep and Widmer [10], viz. $5.35 \mu \mathrm{m}$. The investigated range of yeast slurry concentrations was between 1 and $51 \mathrm{~g}$ (yeast dry weight) per litre of isotonic solution and matched the range used by the major part of the researchers.

The yeast filtration properties were measured by filtration through a Gelman membrane (pore size $0.45 \mu \mathrm{m}$ ). The filtration pressure $\Delta p$ was generated by a vacuum pump and was kept constant during the filtration test. Values of $\Delta p=40$ and $80 \mathrm{kPa}$ were chosen based on experimental conditions mentioned in reviewed publications for $S$. cerevisiae. These values were also based on the value of the so-called critical transmembrane pressure, when further pressure increasing slows down or does not even affect the permeate flux [11].

\section{Background}

The choice between dead-end and cross-flow filtration is often based on a case study method where the diversity in the shape of cells to be separated is neglected. Moreover, average specific cake resistance $\alpha$ for cells of extremely different shape (spheroid and rod-like) is in both cases estimated by the Kozeny-Carman model of the porous medium with a fixed coefficient, in the form $[10,12-14]$. $\alpha=\frac{180(1-\varepsilon)}{\rho_{\mathrm{s}} d_{\mathrm{p}}^{2} \varepsilon^{3}}$

where $\varepsilon$ is the cake porosity; $\rho_{\mathrm{s}}$ is the solid particle density, $\mathrm{kg} / \mathrm{m}^{3} ; d_{\mathrm{p}}$ is the particle diameter and 180 is a coefficient for granular bed packing. Application of Eq. (1) with coefficient 180 means that for both packings of spherical and rod-like particles the tortuosity value is assumed to be the same. Eq. (1) may be represented in a more detailed form as:

$\alpha=\frac{36 K(1-\varepsilon)}{\rho_{\mathrm{s}} d_{\mathrm{p}}^{2} \varepsilon^{3}}=\frac{36 K_{0} T^{2}(1-\varepsilon)}{\rho_{\mathrm{s}} d_{\mathrm{p}}^{2} \varepsilon^{3}}$

where $T$ is the tortuosity; $K=K_{0} T^{2}$ is the Kozeny's coefficient (for granular beds $K=4.2$ to 5.0 [15]; $K_{0}$ is a shape coefficient depending on a cross-section capillary pore shape and, for a cylindrical pore, it may be assumed as $K_{0}=2.0$ [16].

By comparing Eqs. (1) and (2), we have $36 K_{0} T^{2}=180$ from which we get $K=K_{0} T^{2}=5.0$. This means that the application of Eq. (1) implies that $K$ is assumed to be constant. However, as several authors have underlined [17-20], $K$ will depend on the packing density, on the particle shape and, hence, on the tortuosity of the granular bed.

Other important factor affecting the tortuosity is the cake compressibility. Usually, the cake formed by cells on the membrane surface has a high resistance, because of its compressibility, which hinders the process output [21]. Cake compressibility may be characterised with the help of a compressibility index $n$ derived from the relation of specific cake resistance $\alpha$ with the filtration pressure $\Delta p$ :

$\alpha=\alpha^{\prime}(\Delta p)^{n}$

where $\alpha^{\prime}$ is a coefficient and $n$ is the compressibility index. For a range of filtration pressures of $40-80 \mathrm{kPa}$, the average value of the compressibility $n=0.7$ was obtained in our experiments, which coincides with those measured by Shimizu et al. [13] for baker's yeast.

Tanaka et al. [5] measured a compressibility index of $n=0.6$ to 1.2 for bacterial cakes. The lower values corresponded to ellipsoidal cells and the higher ones to rod-shaped cells. Using Escherichia coli in solutions of increasing ionic 
strength, the compressibility index could be as high as 1.7 for high ionic strength solutions [12].

Aron and Davis [22] used $S$. cerevisiae cake layers to investigate protein transport. The filtration cake was built up previously on a Gelman membrane of $0.2 \mu \mathrm{m}$ pore size either by vacuum filtration or by sedimentation from yeast slurry. They observed that the cake layer formed by gravity settling displayed a higher resistance to the protein solute flow as compared with the corresponding value for a yeast layer formed by vacuum filtration. The authors assumed that the cake formed under suction had micropores incorporated in the layer structure, which provided a lower flow resistance. From our point of view, another reasonable explanation may be presented if one takes in account that, in the first case, the growing settled cake was loose sediment, whereas, the cake formed under pressure already displayed a local resistance distribution. This means that, by applying pressure to percolate the protein solution, the gravity settled sediment became compressed and suffered a rearrangement, thereby increasing its resistance.

In Eq. (2), not only the particle size and porosity are used, but also tortuosity. Therefore, $K_{0}$ may be affected by the cake compressibility. A conventional relationship of the specific cake resistance with porosity, as expressed by Eq. (1), may thus lead to miscalculations of the cake parameters, as will be illustrated below.

\section{Results and discussion}

\subsection{Influence of cell shape on the specific cake resistance}

Numerous investigations show that for nearly spherical particles, the cake resistance both in dead-end and cross-flow filtration has similar values. In experiments with polystyrol particles and baker's yeast, Geissler and Werner [23] concluded that $\alpha$ should be the same both in static (deadend) and in cross-flow filtration. Similar results were also obtained by Tanaka et al. for C. glutamicum and S. cerevisiae [5].
When the particles have a wide range of size distribution, a size classifying effect of cross-flow velocity on the particle sizes retained in the cake layer is observed [23,24]. Larger particles are resuspended more easily in the bulk phase, while the smaller ones are deposited preferentially, leading to thinner cake layers with a higher hydraulic resistance [23]. However, in the range of low cross-flow velocity values examined in [23] for a polydisperse poly-methyl-meta-acrylate (PMMA) suspension, where $0.5 \mu \mathrm{m} \leq d_{\mathrm{p}} \leq 50 \mu \mathrm{m}$, the cake resistance was found to be the same in both dead-end and cross-flow filtration. Tanaka et al. [24], in a study of cross-flow filtration of a yeast broth cultivated in molasses, mentioned that, at the initial stage of filtration, the yeast cells and particles from the molasses were deposited on the membrane, forming a cake in a similar way as in dead-end filtration. After the initial stage, the fine particles from molasses formed a thin layer, which had a higher resistance than the firstly formed layer.

The cake resistance of the layer formed by rod-like particles (bacteria), contrary to the yeast cell layer, displays significant differences in deadend and cross-flow filtration [5,25].

The filtration behaviour during the unsteadystate phase of cross-flow filtration of broths of Bacillus subtilis, E. coli and Lactobacillus delbrueckii, which are rod-shaped, was studied by Tanaka et al. [25]. Cake resistance at the initial stage agreed with the one measured in dead-end filtration, but started to increase in comparison with the one measured in dead-end filtration due to the shear-induced arrangement of cells. The extent of the increase in specific resistance became higher and the time taken to start the cell arrangement became shorter with an increasing circulation flow rate. The increase in specific resistance due to the shear-induced arrangement was more appreciable in the cross-flow filtration of the broth of $L$. delbrueckii than the one obtained for $B$. subtilis and $E$. coli. It must be noted at this point that the ratio length/diameter of $L$. delbrueckii is much higher than in the case of bacilli.

The work of Tanaka et al. [5] provides remarkable results and micrographs of cakes for deadend and cross-flow filtration of rod-like bacteria 
Table 1

Calculated values of porosity and tortuosity for B. subtilis, B. brevis and B. cereus cakes

\begin{tabular}{llllll}
\hline Cell suspension & $J_{\mathrm{d}-\mathrm{e}} / J_{\mathrm{c}-\mathrm{f}}{ }^{\mathrm{a}}$ & $\varepsilon_{\mathrm{d}-\mathrm{e}}$ & $\varepsilon_{\mathrm{c}-\mathrm{f}}$ & $\left(T=\varepsilon^{-0.05}\right)_{\mathrm{d}-\mathrm{e}}$ & $\left(T=\varepsilon^{-0.5}\right)_{\mathrm{c}-\mathrm{f}}$ \\
\hline B. subtilis & $1 / 10$ & 0.433 & 0.26 & 1.52 & 1.96 \\
B. brevis & $1 / 5$ & & 0.305 & & 1.81 \\
B. cereus & $1 / 7$ & & 0.28 & & 1.89 \\
\hline
\end{tabular}

a Indexes: c-f-cross-flow filtration; d-e, dead-end filtration.

B. subtilis, B. brevis and B. cereus. The cake resistance in dead-end filtration was lower than in cross-flow filtration. On the other hand, for crossflow filtration, the cake structure changed from random rod packing to horizontally oriented rod packing with a structure close to a 'brick-like' wall. The authors found a significant difference between the measured filtrate flux $J$ and the value calculated by Eq. (4), when the value used for the specific cake resistance was the one determined in dead-end filtration experiments.

$J=\frac{\Delta p}{\mu\left(\alpha w+R_{\mathrm{m}}\right)}$

where $\mu$ is the liquid viscosity; $w$ is the weight of cake per unit filtration area, $\mathrm{kg} / \mathrm{m}^{2} ; R_{\mathrm{m}}$ is the membrane resistance, $1 / \mathrm{m}$.

The authors reported experimental cross-flow fluxes $J_{\text {c-f }}$ for $B$. subtilis, B. brevis and B. cereus that were, respectively, about $1 / 10,1 / 5$ and $1 / 7$ of the calculated ones $\left(J_{\mathrm{d}-\mathrm{e}}\right)$ for a dead-end filtration pressure of $49 \mathrm{kPa}$. As the membrane hydraulic resistance, in comparison to the cake resistance, is small, we can assume $R_{\mathrm{m}}=0$ in Eq. (4) and from that assumption, make estimations of the cake resistance $J_{\mathrm{d}-\mathrm{e}} / J_{\mathrm{c}-\mathrm{f}}=\alpha_{\mathrm{c}-\mathrm{f}} / \alpha_{\mathrm{d}-\mathrm{e}}$. The lack of data on bacterial cake porosity implies that estimation will only have a qualitative meaning. To reduce the number of variables in Eq. (2), we represent the tortuosity as a function of porosity $[19,26]$.

$T=\varepsilon^{-0.5}$

$\frac{J_{\mathrm{d}-\mathrm{e}}}{J_{\mathrm{c}-\mathrm{f}}}=\frac{\alpha_{\mathrm{c}-\mathrm{f}}}{\alpha_{\mathrm{d}-\mathrm{e}}}=\frac{\left[(1-\varepsilon) / \varepsilon^{4}\right]_{\mathrm{c}-\mathrm{f}}}{\left[(1-\varepsilon) / \varepsilon^{4}\right]_{\mathrm{d}-\mathrm{e}}}$

In general, rod-like cells have a ratio $\delta=$ length/diameter around 4:1-6:1 and, to determine the porosity of random rod packing in a dead-end cake, we can use the linear function obtained by $\mathrm{Yu}$ and co-authors [27] for random packing of monosized cylinders.

$\varepsilon=\varepsilon_{\mathrm{d}-\mathrm{e}}=0.3053+0.02557 \delta$

The Function (7) gives a correlation coefficient of 0.9968 and for $\delta=5$ it has the value $\varepsilon_{\mathrm{d}-\mathrm{e}}=0.433$, which can be assumed to be similar for all suspensions tested by Tanaka et al. [5]. It also works as a starting point for the estimation of the crossflow cake porosity.

Let us estimate the cross-flow resistance through Eq. (6). When the dead-end porosity is defined, the cross-flow porosity is the only unknown. We use the appropriate flux ratio $(1 / 10$, $1 / 5$ or $1 / 7)$ and the value for the dead-end porosity calculated from Eq. (7), to calculate the dependence $\left[(1-\varepsilon) / \varepsilon^{4}\right]_{\mathrm{d}-\mathrm{e}}$ on $\varepsilon_{\mathrm{d}-\mathrm{e}}$ and, by replacing the value found in Eq. (6), we can calculate the cross-flow porosity $\varepsilon_{\mathrm{c}-\mathrm{f}}$. The calculated values are shown in Table 1. The obtained porosities have the values $0.26,0.305$ and 0.28 , respectively. The porosity variation is related to the degree of cells orientation towards the membrane surface: in the first photo displayed in the work of Tanaka et al. [5] concerning B. subtilis, an almost perfect brickwall structure is shown, with all the rod-cells piled up in bundles parallel to the membrane surface. In turn, the fourth photo, also of B. subtilis, corresponds to a random packing (dead-end filtration). On the other hand, the third photo, of $B$. cereus, is an intermediate case of semi-ordered packing.

To compare the obtained porosities with the expected boundary value, an approach used for 
the investigation of percolation through a lattice of non-overlapping particles was applied [28]. Let us consider the rod cells as cylinders arranged in horizontal layers. The hypothetical porous medium will consist in elementary unit cells, each of which represented by a prism circumscribing the cylindrical bacterial cell. By comparing the cylinder with the unit cell volume, we have, for the porosity of the uncompressed cake, the value $\varepsilon_{0}=1-\pi / 4=0.251$ (see Fig. 2). This result can be considered a reasonable lower bound for porosity.

Based on the porosity values calculated from Eq. (7), the tortuosity can be recalculated from Eq. (5) as 1.52 for dead-end cake, and as 1.96, 1.81 and 1.89 for cross-flow cakes of B. subtilis, $B$. brevis and $B$. cereus, respectively. These data show how significant the role of tortuosity may be on cake characterisation.

\subsection{Porosity calculated from Eq. (1) for compressible cake}

Other example of the tortuosity involvement in specific cake resistance properties is the cake compressibility.

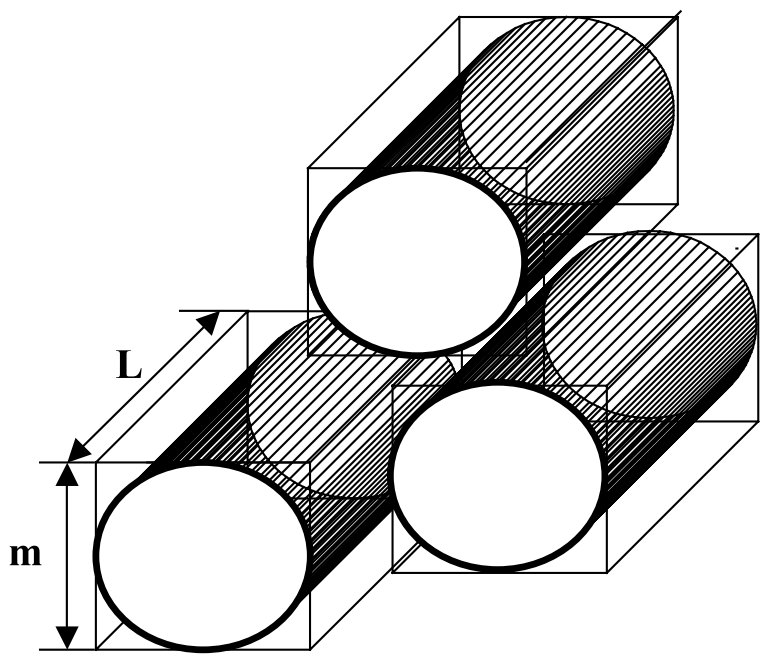

Fig. 2. Schematic representation of rod-like cells piled up in a brick-like wall structure. As may be seen, the porosity can be estimated as $\varepsilon=1-\left(\pi m^{2} L / 4\right) /\left(m^{2} L\right)=1-\pi / 4=0.251$.

\subsubsection{Rod-like particles}

The first example used data published by Shimizu et al. [13]. The specific cake resistance experimentally measured and Eq. (1) were used to calculate the cake porosity. The authors calculated $\varepsilon$ as being 0.15 and 0.05 for baker's yeast and rod-like $B$. caldolitycus $\mathrm{M} 1$, respectively, at a filtration pressure of $100 \mathrm{kPa}$. The compressibility index was 0.7 (for baker's yeast) and 1.0 (for $B$. caldolitycus $\mathrm{M} 1$ ). The calculated $\varepsilon=0.05$ seems to be too small for the reported cake resistance of around $2.7 \times 10^{14} \mathrm{~m} / \mathrm{kg}$. By rearranging Eq. (2) with $\alpha=2.7 \times 10^{14} \mathrm{~m} / \mathrm{kg}$, as above, $d_{\mathrm{p}}=1 \mu \mathrm{m}$ and $\rho_{\mathrm{s}}=1000 \mathrm{~kg} / \mathrm{m}^{3}$ we obtain:

$\frac{T^{2}(1-\varepsilon)}{\varepsilon^{3}}=3750$

We shall now consider two boundary conditions: the condition defined by Eq. (5), when $T=\varepsilon^{-0.5}$ and another condition when a more strong dependency of tortuosity on porosity is assumed, $T=\varepsilon^{-0.75}$. Using Eq. (8) above, we have $(1-\varepsilon) / \varepsilon^{4}=3750$ and thus, $\varepsilon \approx 0.124, T=2.84$. For the second condition, we get $(1-\varepsilon) / \varepsilon^{4.5}=$ 3750 and $\varepsilon \approx 0.155, T=4.0$, respectively. These estimated values seem to be more reasonable than $\varepsilon=0.05$. Furthermore, Fane et al. [12] measured the average $E$. coli cake porosity for different filtration pressures, different membrane types and variable solution ionic strength. They obtained the following range of values for the cake porosity $\varepsilon$, for $\Delta p=30 \mathrm{kPa}, \varepsilon \approx 0.1$ to 0.18 and, for $\Delta p=$ $100 \mathrm{kPa}, \varepsilon \approx 0.08$ to 0.12 . The experimental results obtained by Fane et al. [12], for rod-like bacteria such as E. coli, agree with those calculated in the present work.

\subsubsection{Spheroid particles}

For a baker's yeast suspension (average cell size $3.8 \mu \mathrm{m}$, filtration pressure $100 \mathrm{kPa}$ and $\alpha \approx 3.2 \times$ $10^{12} \mathrm{~m} / \mathrm{kg}$ ), using Eq. (1), Shimizu et al. [13] calculated a cake porosity of 0.15 . In turn, Geissler and Werner [23], for baker's yeast with a volume fraction in suspension of 0.007 and a filtration pressure of around $10-50 \mathrm{kPa}(0.1-0.5$ bar), indicated that yeast cake porosity was comprised in the range of $(0.300-0.285)$. 
With these low values of filtration pressure, the expected porosity can be estimated by assuming an uncompressible filter cake. Based on microscopic measurements, a ratio of the minimum to the maximum yeast cell diameter was found to be approximately $0.7-0.8$ [14]. Our own measurements gave a ratio of 0.7 . We may consider the yeast cell as a body consisting on two hemispheres on the ends and on a cylindrical part between them. By assuming now that the hypothetical porous medium consists in elementary unit cells represented by a circumscribed prism around the baker's yeast cell, it was possible to estimate the expected uncompressed yeast cell packing porosity as $\varepsilon_{0}=0.284$ which agrees with Geissler and Werner [23] and with our measurement of $\varepsilon=$ $0.283(\Delta p=40 \mathrm{kPa})$. A linear extrapolation of the experimentally measured porosity to the pressure of $100 \mathrm{kPa}$ gives a porosity of about 0.2 , which is higher than the calculated by Shimizu et al. [13]. The differences may be related to the neglected tortuosity effect. Applying Eq. (5), we have, for $\alpha=3.2 \times 10^{12} \mathrm{~kg} / \mathrm{m} \varepsilon=0.19$ and $T=2.29$, which corresponds to $K=10.5$ or $(36 K)=379$, a value two times higher than the coefficient indicated180 - in Eq. (1).

The following values of the Kozeny-Carman coefficient were obtained in our experiments: for a filtration pressure of $40 \mathrm{kPa}-(36 K)=204$ and $K \approx 5.67$. For a filtration pressure of $80 \mathrm{kPa}-$ $(36 K)=272$ and $K \approx 7.55$. As can be seen, the coefficient $K$ has a tendency to increase with the increasing filtration pressure. We may speculate that this increase results from the increase in pore tortuosity rather than from changes in the pore size.

\section{Conclusions}

The examples discussed above lead us to the following conclusions.

- By neglecting the variation in tortuosity, significant miscalculations of cake porosity and of specific cake resistance might occur;

- Rod-like particles in cross-flow filtration may be affected by shear-induced arrangement. A denser packing gives rise to brick-like wall structures, with a higher tortuosity, which in turn leads to higher cake resistance;

- The consideration of tortuosity as a variable parameter in compressible cakes provides a more precise representation of cake behaviour. Tortuosity becomes more significant with an increasing applied filtration pressure.

\section{Acknowledgements}

The authors thank the grant given to Alexander Yelshin by the NATO Science fellowships Programme.

\section{References}

[1] B. Gautier, Aspects Pratiques de la Filtration des Vins, Bourgogne-Publications, France, 1984.

[2] G.J. Freeman, M.T. Mckechnie, S.M. Smedley, et al., Determination and use of process characteristics for optimization of the beer filtration operation, Trans. IchemE. Part C 73 (1995) 157-164.

[3] Memtech Ltd. The use of crossflow membranes to clarify and stabilize beer, Filtration Separation, 35 (1998) 860861.

[4] R.W. Schlenker, Tangential flow filtration for beer recovery from spent yeast, Filtrat. Separat. 35 (1998) 863-865.

[5] T. Tanaka, K.-I. Abe, H. Asakawa, et al., Filtration characteristics and structure of cake in crossflow filtration of bacterial suspension, J. Ferment. Bioeng. 78 (1994) $455-461$.

[6] W.S.W. Ho, K.K. Sirkar, Membrane Handbook, WNR, New York, 1992.

[7] A. Rushton, A.S. Ward, R.G. Holdich, Solid-Liquid Filtration and Separation Technology, VCH, Weinheim, 1996.

[8] F.M. Tiller, H.R. Cooper, The role of porosity in filtration. Part V, Porosity variation in filter cakes, Am. Inst. Chem. Eng. J. 8 (1962) 445-449.

[9] F.M. Tiller, C.S. Yeh, The role of porosity in filtration. Part X. Deposition of compressible cakes on external radial surface, Am. Inst. Chem. Eng. J. 31 (1985) 12411248.

[10] T. Schluep, F. Widmer, Initial transient effects during cross flow microfiltration of yeast suspensions, J. Membr. Sci. 115 (1996) 133-145.

[11] K.A. Caridis, T.D. Papathanasiou, Pressure effects in cross-flow microfiltration of suspensions of whole bacterial-cells, Bioprocess Eng. 16 (1997) 199-208.

[12] A.G. Fane, C.J.D. Fell, P.H. Hodgson, et al., Microfiltration of biomass and biofluids: effects of membrane morphology and operating conditions, Filtrat. Separat. 28 (1991) 332-340. 
[13] Y. Shimizu, K.-I. Shimodera, A. Watanabe, Cross-flow microfiltration of bacterial cells, J. Ferment. Bioeng. 76 (1993) 493-500.

[14] S.S. Madaeni, Mechanism of virus removal using membranes, Filtrat. Separat. 34 (1997) 61-65.

[15] S.-H. Chiang, D. He, Filtration and dewatering: theory and practice, Filtrat. Separat. 6 (1993) 64-83.

[16] J. Happel, H. Brenner, Low Reynolds Number Hydrodynamics, Prentice-Hall, 1965.

[17] J.A. Currie, Gaseous diffusion in porous media. Part 2-Dry granular materials, Br. J. Appl. Phys. 11 (1960) 318-324.

[18] C.N. Satterfield, Heterogeneous Catalysis in Practice, McGraw-Hill, 1980.

[19] M. Mota, J.A. Teixeira A. Yelshin, Tortuosity in bioseparations and its application to food processes, in: Feyo de Azevedo, E. Ferreira, K. Luben, P. Osseweijer (Eds.), Proceedings of Second European Symposium on Biochemical Engineering Science, Porto, 16-19 September 1998, University of Porto, Porto, 1998, pp. 93-98.

[20] M. Mota, J.A. Teixeira, A. Yelshin, Image analysis of packed beds of spherical particles of different sizes, Separat. Purif. Technol. 15 (1999) 59-68.

[21] E.L.V. Harris, S.E. Angal, Protein Purification Methods. A Practical Approach, ILR Press at Oxford Univ. Press, 1989, pp. 130-140.
[22] N. Arora, R.H. Davis, Deadend microfiltration of bovine serum albumin suspension through yeast cake layers and asymmetric polymeric membranes, in: W.W.F. Leung (Ed.), Advances in Filtration and Separation Technology, AFS, Kingwood, TX, USA, 1993, pp. 353-356.

[23] S. Geissler, U. Werner, Dynamic model of crossflow microfiltration in flat-channel systems under laminar flow conditions, Filtrat. Separat. 32 (1995) 533-537.

[24] T. Tanaka, R. Kamimura, R. Fujiwara, K. Nakanishi, Crossflow filtration of yeast broth cultivated in molasses, Biotechnol. Bioeng. 43 (1994) 1094-1101.

[25] T. Tanaka, K. Usui, K. Kouda, K. Nakanishi, Filtration behaviors of rod-shaped bacterial broths in unsteady-state phase of cross-flow filtration, J. Chem. Eng. Japan 29 (1996) 973-981.

[26] M. Mota, J.A. Teixeira, R. Bowen A. Yelshin, Effect of tortuosity on transport 0properties of mixed granular beds, in: Proceedings of eighth World Filtration Congress, 3-7 April 2000, 1, Filtration Society, Brighton, UK, 2000, pp. 57-60.

[27] A.B. Yu, R.P. Zou, N. Standish, Modifying the linear packing model for predicting the porosity of nonspherical particle mixtures, Ind. Eng. Chem. Res. 35 (1996) 37303741.

[28] E.J. Garboczi, M.F. Thorpe, M.S. DeVries, A.R. Day, Universal conductivity curve for a plane containing random holes, Phys. Rev. A 43 (1991) 6473-6482. 